\title{
Regularities of microdefect formation in silicon during heat treatment for internal getter synthesis
}

\author{
Vladimir T. Bublik ${ }^{1}$, Marina I. Voronova ${ }^{1}$, Kirill D. Shcherbachev ${ }^{1}$, Mikhail V. Mezhennyi ${ }^{2}$, \\ Vladimir Ya. Reznik ${ }^{2}$ \\ 1 National University of Science and Technology MISiS, 4 Leninsky Prospekt, Moscow 119049, Russia \\ 2 JSC Optron, 53 Shcherbakovskaya Str., Moscow 105187, Russia \\ Corresponding author: Kirill D. Shcherbachev (chterb@gmail.com)
}

Received 27 June 2019 • Accepted 16 Junly 2019 • Published 12 September 2019

Citation: Bublik VT, Voronova MI, Shcherbachev KD, Mezhennyi MV, Reznik VYa (2019) Regularities of microdefect formation in silicon during heat treatment for internal getter synthesis. Modern Electronic Materials 5(3): 133-139. https://doi.org/10.3897/j. moem.5.3.52812

\begin{abstract}
Gettering is defined as a process by which metal impurities in the device region are reduced by localizing them in predetermined, passive regions of the silicon wafer. Internal or intrinsic gettering is an effective way to reduce the contamination in active regions. The generation of internal getters is based on the decomposition of the supersaturated oxygen solid solution in silicon, which favours the formation of a complex defect system in silicon that consists of various precipitate/dislocation agglomerates. Regularities of microdefect formation during oxygen solid solution decomposition in silicon have been studied. We show that actual solid solution supersaturation, temperature and heat treatment duration determine the structure of the solid solution. Combining these factors, including heat treatment parameters, one can control solid solution decomposition rate and $\mathrm{SiO}_{x}$ precipitate sizes and quantity. The methods of X-ray diffuse scattering and transmission electron microscopy have shown high efficiency for studying the effect of heat treatment in crystals. For annealing at $450{ }^{\circ} \mathrm{C}$, solid solution decomposition occurs at high supersaturation degrees, and concentration inhomogeneity regions may form at an early decomposition stage over the actual annealing time (up to $40 \mathrm{~h}$ ). With an increase in the temperature of subsequent annealing to $650{ }^{\circ} \mathrm{C}$, local regions with above-average oxygen supersaturation degrees increase the efficiency of oxygen solid solution decomposition. Further, an increase in annealing temperature to $T>1000{ }^{\circ} \mathrm{C}$ results in a more intense generation of the largest precipitates at the expense of the smaller ones. Once the precipitate sizes become sufficiently large, the elastic stresses start to relax, leading to partial incoherence and the generation of dislocations around the particles. This type of defect structure seems to be the most efficient getter.
\end{abstract}

\section{Keywords}

$\mathrm{X}$-ray diffuse scattering, silicon, heat treatment, getter

\section{Introduction}

Heat treatments for internal getter synthesis through the decomposition of a supersaturated oxygen solid solution in silicon matrix require combining temperature and duration so as to produce an efficient gettering environ- ment (sizes and quantity of microdefects) providing for reliable trapping of detrimental impurities during further treatments [1-4].

A theoretical analysis of the thermodynamic and kinetic conditions controlling the formation of microdefects, i.e., oxygen-containing precipitates in silicon, was 
reported earlier [5-8]. The authors $[5,6]$ pointed out the following important factors of this process:

- formation of silicon and oxygen atom associations that affect the temperature dependence of the oxygen solubility limit in silicon and hence the possible supersaturation degree and solid solution decomposition rate;

- formation and growth of precipitates are controlled by two temperature dependent factors: diffusion rates of molecules to microdefects and speed of molecule to precipitate attachment.

Analysis [5, 6] does not provide detailed solid solution decomposition mechanisms which seem to control the energy parameters of critical-size precipitate formation reactions, this critical precipitate size being temperature dependent.

Thus, selection of the optimum internal getter synthesis mode should take into account the abovementioned factors which may control the oxygen solid solution decomposition rate and the size and quantity of precipitates which determine the gettering properties of the structure. Unfortunately the solubility limit of oxygen in silicon, its dependence on the formation of complexes and the energy parameters of the abovementioned factors have not yet been studied well. It is therefore impossible to simulate the resultant structure after gettering heat treatments. Most getter formation works are experimental ones. Therefore objective and information valuable structural control methods are required.

Thus, given similar initial supersaturation degree and high-temperature heat treatment duration the decomposition rate of oxygen solid solution in silicon and the resultant crystal structure will mostly depend on the processes occurring during low-temperature heat treatments. Obviously, as the molecule attachment energy at $1000{ }^{\circ} \mathrm{C}$ is not the determinant factor, diffusion processes will dominate. For example, the formation of high local supersaturation regions reduces the probability of the formation and growth of silicon oxide precipitates through diffusion.

The structure of crystals after the complete heat treatment cycle for internal getter synthesis is of great interest since the decomposition of an oxygen solid solution in silicon leads to the formation of various microdefect complexes: $\mathrm{SiO}_{x}$ precipitates, precipitate/dislocation associations and $\sim 2-3 \mu \mathrm{m}$ stacking faults. Further heat treatments do not change the quantity of microdefects and the type of oxygen-containing precipitates but dramatically increase the quantity of small microdefects that form during the growth of the oxide particles and originate from intrinsic point defects $[9,10]$. In lower supersaturation regions (at wafer edges) the density of the microdefects is lower but their types are still numerous. Data on metallographic analysis of etching patterns and the distribution of X-ray diffuse scattering in the vicinity of reciprocal lattice sites suggest that a complex system of microdefects forms in the material. The asymmetric pattern of the diffuse scattering isointensity contours suggests a relaxation of elas- tic fields in the vicinity of the $\mathrm{SiO}_{x}$ particles, i.e., dislocation generation, if elastic field strength exceeds a critical value. A non-dislocation related stress relaxation mechanism is also possible and is associated with the supply of point defects [11]. Obviously, the density of the precipitates per unit volume depends on the supersaturation degree and the critical-size precipitate formation energy, and the results of the secondary processes during which dislocations and point defects form [9] are controlled by kinetic factors.

Below we present experimental data for a series of silicon crystals. When choosing the experimental heat treatment modes we took into account earlier results $[12,13]$. We assumed that the heat treatment temperature chosen was sufficient for the formation of $\mathrm{SiO}_{x}$ type precipitates, i.e., the energy barrier of molecules to precipitates attachment can be overcome. However the diffusion mobility of the molecules is high enough for the precipitates to grow to the critical size during heat treatment at the selected temperature. The type of the precipitates was not detailed. The optimal temperature was considered to be the one at which the supersaturation is the highest.

Our experimental data differ from earlier ones [12] because that our heat treatment cycles did not include the preliminary short-term anneal at $T=1000{ }^{\circ} \mathrm{C}(15 \mathrm{~min})$. This work continues our study of structure formation during decomposition of oxygen solid solution in silicon for different heat treatment combinations.

\section{Experimental}

The test materials were double-side chemically polished fragments of $150 \mathrm{~mm}$ dislocation-free $\mathrm{Cz}-\mathrm{Si}(100)$ wafers grown in "vacancy" mode. The oxygen concentration in the crystals was approx. (7-9) $\cdot 10^{17} \mathrm{~cm}^{-3}$ and the electrical resistivity was $1-5 \mathrm{Ohm} \cdot \mathrm{cm}$. The specimens were heat treated in various modes as summarized below.

$$
\begin{array}{cl}
\text { Specimen \# } & \text { Heat treatment mode } \\
1 & 650{ }^{\circ} \mathrm{C}(40 \mathrm{~h}) \\
2 & 650{ }^{\circ} \mathrm{C}(2 \mathrm{~h})+1000^{\circ} \mathrm{C}(16 \mathrm{~h}) \\
3 & 650{ }^{\circ} \mathrm{C}(16 \mathrm{~h})+1000^{\circ} \mathrm{C}(0.5 \mathrm{~h}) \\
4 & 650{ }^{\circ} \mathrm{C}(16 \mathrm{~h})+1000^{\circ} \mathrm{C}(16 \mathrm{~h})
\end{array}
$$

The structure was studied using X-ray diffuse scattering on a D8 Discover multifunctional X-ray diffractometer (Bruker-AXS, Germany) in triple-crystal setup. The $\mathrm{X}$-ray source was a $1.6 \mathrm{~kW}$ copper tube. A parallel beam was formed by a Goebel mirror. The measurements were carried out in a high-resolution setup. A $(n ;+n)$ monochromator with two $\mathrm{Ge}(220)$ crystals (double-reflection channel-cut monochromators) cut off the $\mathrm{Cu} K_{\alpha 1}$ radiation component. The instrumental function width of the device is $\sim 12$ arc sec in this setup. A Ge(220) channel-cut triple analyzer crystal was installed before the detector.

The X-ray diffuse scattering distribution was studied in the vicinity of the $\mathrm{Si}(004)$ reciprocal lattice site. The recipro- 
cal space maps were built along with their sections perpendicular to the diffraction vector ( $q_{x}$ sections) and at a small angle to the diffraction vector ( $q_{z}$ sections). The symmetrical and asymmetrical X-ray diffuse scattering components were separated in the reciprocal space maps. The measurement method was described in detail earlier $[12,14]$.

Structural defects forming due to the decomposition of the supersaturated oxygen solid solution in silicon during heat treatments were additionally studied using TEM. Silicon specimens were chemically polished to thin foils for TEM and examined under a JEM 200-CX electron microscope at a $200 \mathrm{kV}$ acceleration voltage. The origin of lattice defects was studied by analyzing the electron microscopy images for different diffraction contrast conditions occurring at variation of the diffraction vector $g$ and the Bragg angle deviation $\theta$.

\section{Results and discussion}

Figure 1 shows X-ray diffuse scattering data. It can be seen that the X-ray diffuse scattering intensity $I$ is very low and comparable with the pseudopeak intensity [15]. Specimen 1 differed from the specimens of earlier work [12] by a longer $650{ }^{\circ} \mathrm{C}$ heat treatment ( $40 \mathrm{~h}$ against $16 \mathrm{~h}$ earlier). The $\lg I=f\left(\lg q_{x}\right)$ curve slope as shown in Fig. $2 a$ is close to 1 in the $q_{x}>2 \mu \mathrm{m}^{-1}$ section. At these $q_{x}$ values the contribution of the instrumental function is negligible. Thus the microdefects were not large, in agreement with earlier size estimates [12]. It is safe to assume that the microdefects were less than $20-30 \mathrm{~nm}$ in size. Figure $2 b$ shows that the X-ray diffuse scattering intensity at $q_{z}>0\left(q_{z}\right.$ is the vector describing the X-ray diffuse scattering measurement point deviation from the reciprocal lattice site along the reciprocal lattice vector) is somewhat higher. This suggests that the microdefects were larger but
TEM did not reveal them. Probably at this solid solution decomposition stage the microdefects were coherent with the matrix, had smeared boundaries (low displacement field gradients) and were therefore not resolved in TEM diffraction contrast.

TEM studies of Specimen 2 heat treated at $650{ }^{\circ} \mathrm{C}(2 \mathrm{~h})$ $+1000{ }^{\circ} \mathrm{C}(16 \mathrm{~h})$ showed that the crystals contained 130 $150 \mathrm{~nm}$ plate-like precipitates and emerging dislocations, which formed complex-shaped linear/globular pile-ups (Fig. 3a) up to $2000 \mathrm{~nm}$ in length. The defect density as determined by TEM was approx. $8 \cdot 10^{8} \mathrm{~cm}^{-3}$.

Now we analyze X-ray diffuse scattering intensity distribution for the (400) reciprocal lattice site of Specimen 2. The position of the diffuse scattering isointensity contours relative to the reciprocal lattice site suggests that the microdefects had a positive power (Fig. 4). This indicates that stress relaxation around precipitates did not complete. The $q_{x}$ section (Fig. $2 a$ ) of the X-ray diffuse scattering intensity distribution for the (400) reciprocal lattice site has two unclear sections outside the instrumental function profile. One section with the $\lg I=f\left(\lg q_{x}\right)$ curve slope close to $\sim 3$ is the intermediate one between the Huang [16] and asymptotic functions and seemingly originates from superimposition of scattering at larger and smaller defects. The curve slope depends on the volume ratio of the contributing defect types. Seemingly the larger microdefects in the case considered were $130-150 \mathrm{~nm}$ precipitates as shown by TEM. This section corresponds to $1<$ $q_{x}<10 \mu \mathrm{m}^{-1}$. Furthermore the curve has a tail produced by scattering at small microdefecrs sized like those observed in the bulk of Specimen 1 (for $q_{x}>10 \mu \mathrm{m}^{-1}$ ). Thus the specimen contained not only large microdefects but also small 20-30 nm ones.

Obviously all the microdefects forming at $650{ }^{\circ} \mathrm{C}$ can act as precipitation centers that attract $\mathrm{SiO}_{x}$ molecules. They largely control the oxygen solid solution decom-
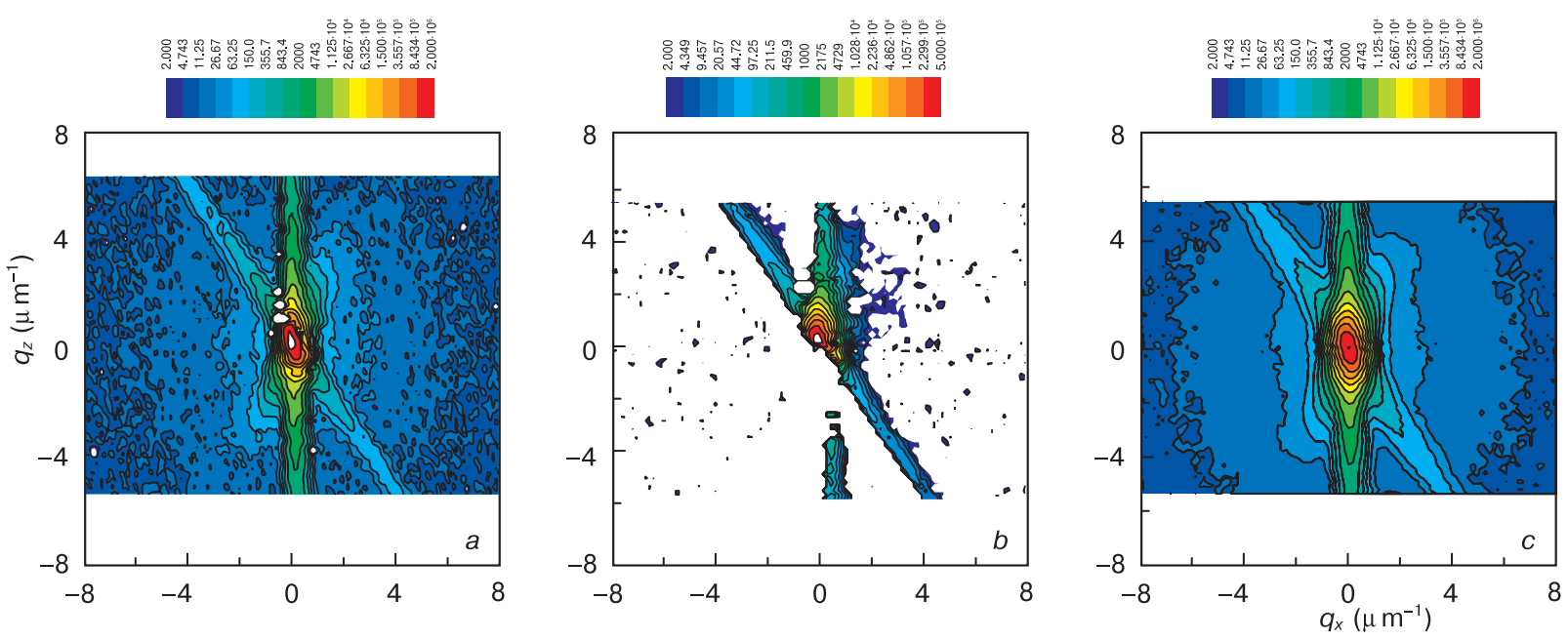

Figure 1. X-ray diffuse scattering intensity distribution for Si Specimen 1 as-annealed at $650{ }^{\circ} \mathrm{C}(40 \mathrm{~h})$ : (a) reciprocal space map (diffuse scattering isointensity contours and pseudopeak); $(b)$ and $(c)$ asymmetrical and symmetrical X-ray diffuse scattering components, respectively. 

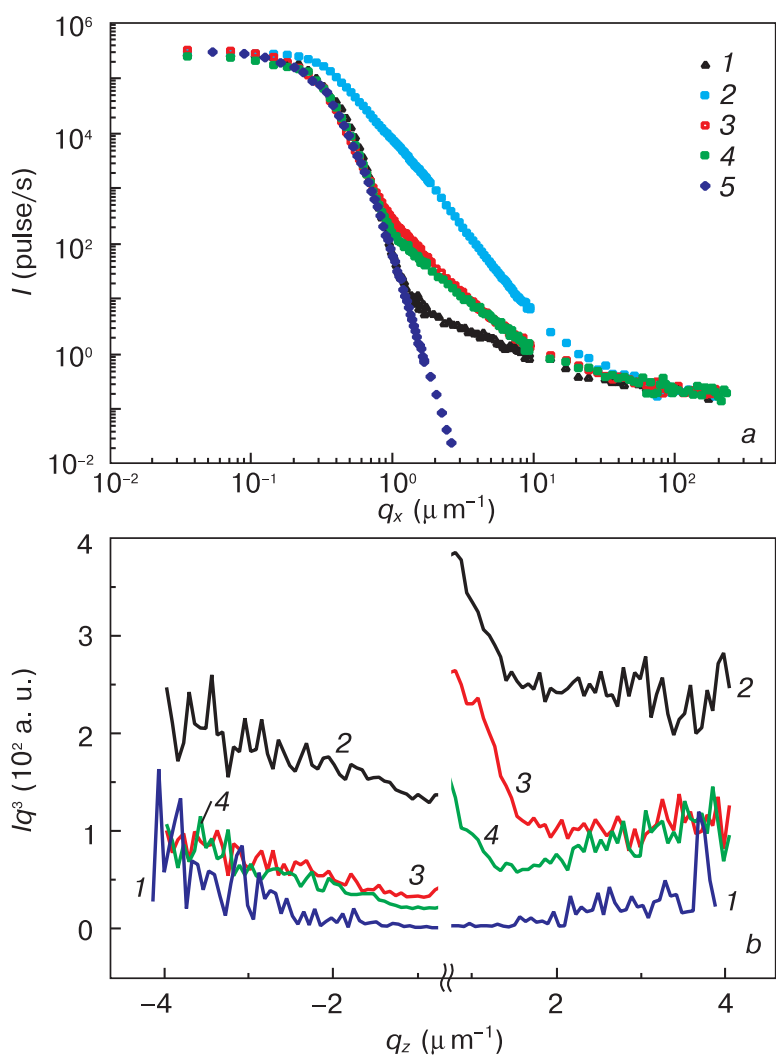

Figure 2. (a) $q_{x}$ and (b) $q_{z}$ reciprocal space map sections for Si specimens after different heat treatments: (1) $650{ }^{\circ} \mathrm{C}(40 \mathrm{~h}) ;(2)$ $650{ }^{\circ} \mathrm{C}(16 \mathrm{~h})+1000{ }^{\circ} \mathrm{C}(0.5 \mathrm{~h}) ;(3) 650{ }^{\circ} \mathrm{C}(2 \mathrm{~h})+1000{ }^{\circ} \mathrm{C}(16 \mathrm{~h}) ;$ (4) $650{ }^{\circ} \mathrm{C}(16 \mathrm{~h})+1000{ }^{\circ} \mathrm{C}(16 \mathrm{~h})$; (5) instrumental function.

position rate at $1000{ }^{\circ} \mathrm{C}$. This assumption is confirmed by the data on Specimen 3 for which the duration of the low-temperature anneal was increased to $16 \mathrm{~h}$. TEM showed that this crystal contained $\sim 200 \mathrm{~nm}$ plate-like precipitates (Fig. 3b). As these precipitates were larger than those in Specimen 2, the stress relaxation and dislocation pile-up around the largest precipitates were more pronounced and the length of the dislocation pile-ups increased to $\sim 5 \cdot 10^{3} \mathrm{~nm}$. The defect density also increased to $6 \cdot 10^{10} \mathrm{~cm}^{-3}$. Two-dimensional defects up to $2000 \mathrm{~nm}$ in size appeared. The total defect density increased to $1.7 \cdot 10^{11} \mathrm{~cm}^{-3}$. The total X-ray diffuse scattering intensity (Fig. $2 a$ ) increased by approx. 1.5 orders of magnitude. The $\lg I=f\left(\lg q_{x}\right)$ curve slope was $\sim 3$ corresponding to asymptotic diffuse scattering [16] whose intensity is proportional to defect power and quantity. And, since the TEM data show that the particle sizes grew by less than several times, the experimentally observed X-ray diffuse scattering intensity growth indicates an increase in the quantity and total volume of the particles by more than one order. Furthermore since the gravity center of the diffuse scattering isointensity contours was shifted from the reciprocal lattice site towards greater scattering vector magnitudes $q_{z}>0$ (Fig. 5), the defects had a positive power. Analysis of the curves shown in Fig. $2 b$ showed that the asymmetry degree of the $\lg I=f\left(\lg q_{z}\right)$ function for Specimens 2 and 4
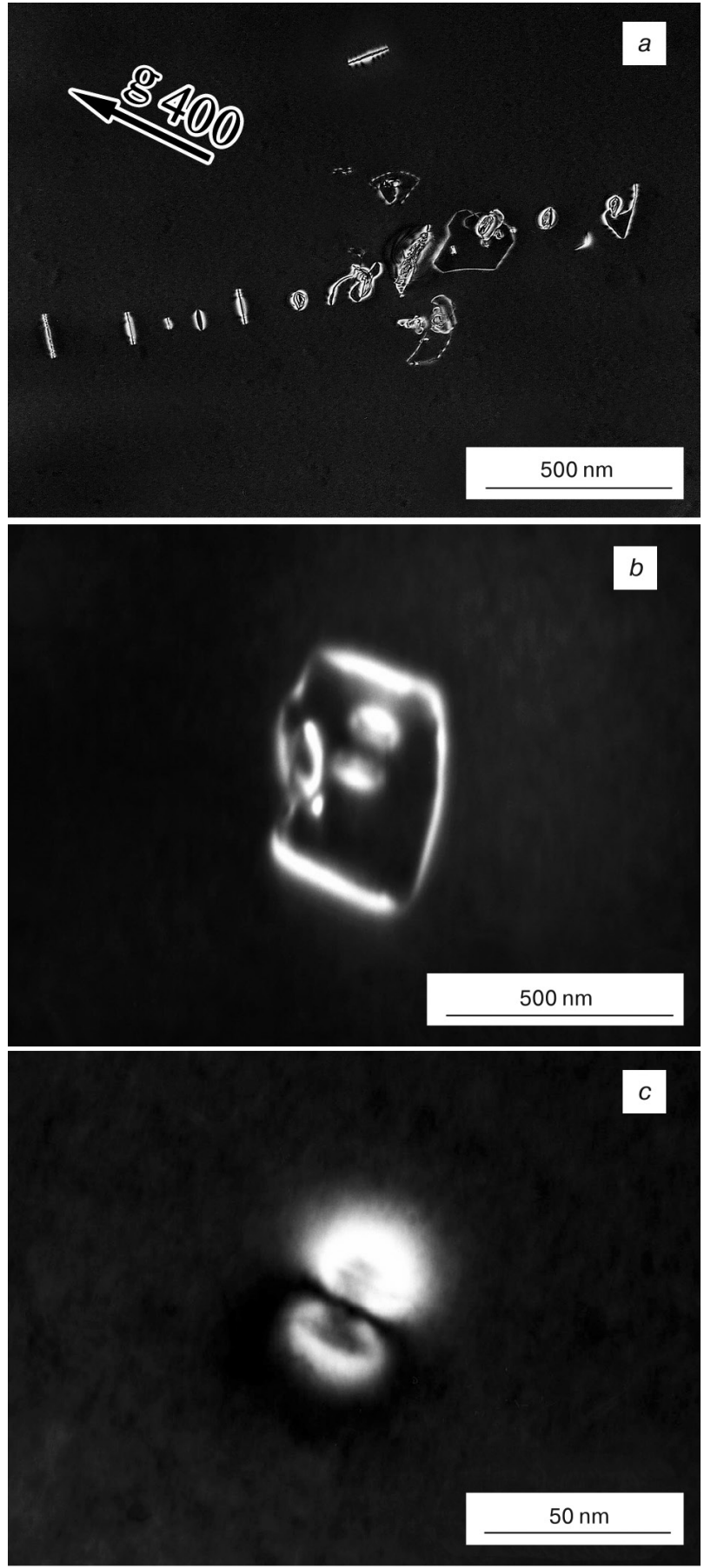

Figure 3. Diffraction contrast TEM image of precipitates in $\mathrm{Si}$ specimens: (a) dislocation loops diverging from a precipitate in Specimen 3; (b) dislocation loop around a particle in Specimen 2; (c) coherent particle in Specimen 4.

did not decrease with the duration of $650{ }^{\circ} \mathrm{C}$ anneal. One can conclude that the degree of elastic stress relaxation did not increase in spite of an increase in the number of dislocations around the microdefects because the magnitude of the elastic stresses also grew due to an increase in the microdefect size. This determined the asymmetry degree of the $\lg I=f\left(\lg q_{z}\right)$ function (Fig. $\left.2 b\right)$.

Thus the main result of an increase in the duration of low-temperature $650{ }^{\circ} \mathrm{C}$ anneal from $2 \mathrm{~h}$ to $16 \mathrm{~h}$ was the 

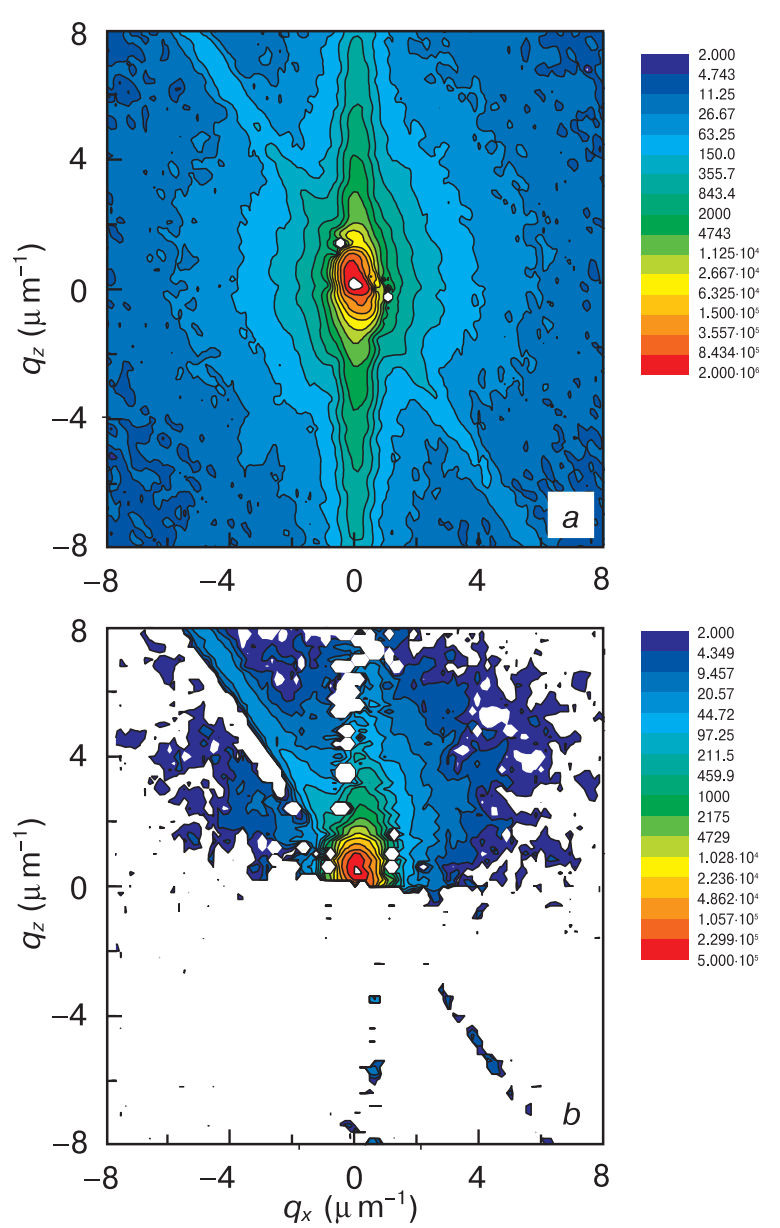

Figure 4. X-ray diffuse scattering intensity distribution for $\mathrm{Si}$ Specimen 2 as-annealed at $650{ }^{\circ} \mathrm{C}(2 \mathrm{~h})+1000{ }^{\circ} \mathrm{C}(16 \mathrm{~h})$ : (a) reciprocal space map; $(b)$ asymmetrical X-ray diffuse scattering component.

formation of more decomposition center precipitates. The data for Specimen 1 suggest that the microdefects remained small and coherent with the matrix.

These results suggest that, most likely, an increase in annealing time for a specific supersaturation degree favors homogeneous precipitation of coherent particles whose quantity grows but size growth is limited due to the low diffusion mobility of oxygen (in the form of single atoms or complexes with interstitial silicon). The precipitates really grow at $1000^{\circ} \mathrm{C}$ for which the diffusion rate is higher. Compare the X-ray diffuse scattering data for Specimens 2 and 4. The X-ray diffuse scattering intensities of Specimens 2 and 4 are almost similar. Thus an increase in the quantity of the precipitates due to an increase in annealing time from $2 \mathrm{~h}$ to $16 \mathrm{~h}$ is compensated by the fact that the microdefect volumes are comparable (Figs $2 a, 4,6$ ) due to the short $1000{ }^{\circ} \mathrm{C}$ annealing time $(0.5 \mathrm{~h}$, Specimen 4). This is also in a good agreement with the data on the structure of Specimens 3 and 4.

Indeed, TEM studies suggest that the precipitate sizes in Specimen 4 reached $25 \mathrm{~nm}$ (Fig. 3c). Comparison of the precipitate sizes in Specimens 3 and 4 shows that
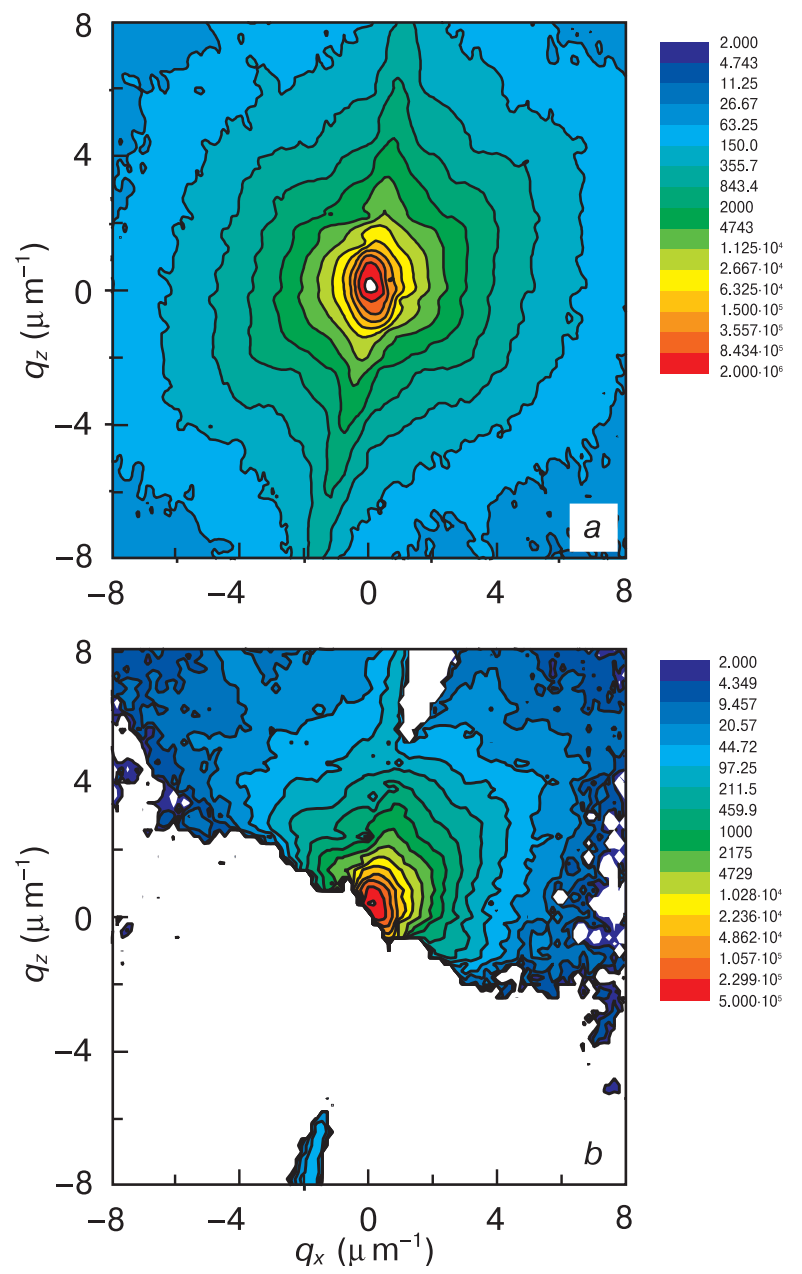

Figure 5. X-ray diffuse scattering intensity distribution for Si Specimen 3 as-annealed at $650{ }^{\circ} \mathrm{C}(16 \mathrm{~h})+1000^{\circ} \mathrm{C}(16 \mathrm{~h})$ : (a) reciprocal space map; $(b)$ asymmetrical X-ray diffuse scattering component.

precipitate growth was controlled by the rate of particle diffusion towards the precipitates. This is confirmed by earlier data [5] according to which the diameter of constant-thickness planar disc-shaped particles increases in proportion to the square rood of annealing time if the predominant factor is the diffusion rate and not the rate of the particle to precipitate attachment reaction. In the case considered, $\left(t_{2} / t_{1}\right)^{1 / 2} \sim 5.7$ (where $t_{1}$ and $t_{2}$ are the durations of $1000{ }^{\circ} \mathrm{C}$ anneals for Specimens 3 and 4 , respectively). The precipitate size ratio for the specimens as determined by TEM is 8 (the precipitate sizes are $200 \mathrm{~nm}$ for Specimen 4 and $25 \mathrm{~nm}$ for Specimen 3). This can be considered as a good agreement with allowance for size measurement error and scatter.

On the other hand, comparison of X-ray diffuse scattering data showed that the total volume of the largest microdefects producing asymptotic scattering (for $q_{x} \sim 1 \mu \mathrm{m}^{-1}$ the $\lg I=f\left(\lg q_{x}\right)$ curve slope is $\sim 3$, Fig. $\left.2 a\right)$ increased by almost 25 times. The $\lg I=f\left(\lg q_{x}\right)$ curve slope for Specimen 4 decreases gradually (Fig. $2 a$ ) with an increase in $q_{x}$. Thus Specimen 4 also containsed smaller particles producing Huang scattering. The X-ray diffuse scattering 

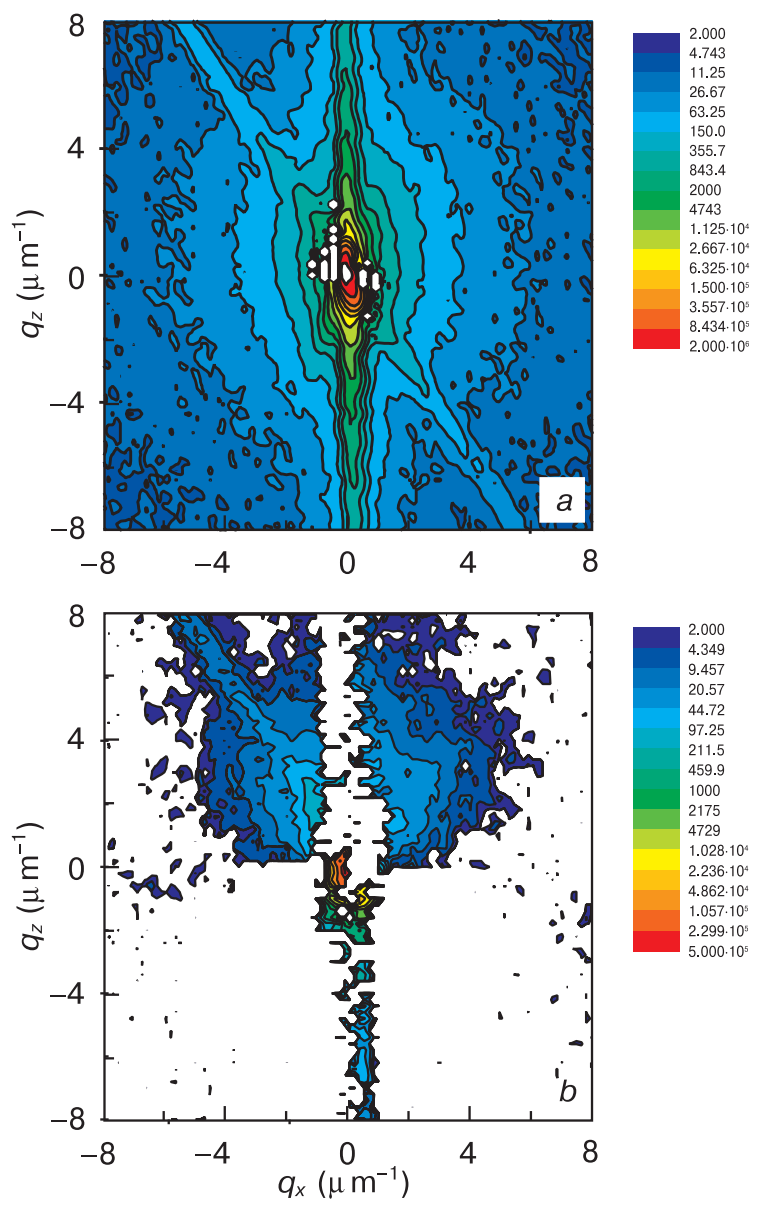

Figure 6. X-ray diffuse scattering intensity distribution for Si Specimen 4 as-annealed at $650{ }^{\circ} \mathrm{C}(16 \mathrm{~h})+1000^{\circ} \mathrm{C}(0.5 \mathrm{~h})$ : (a) reciprocal space map; (b) asymmetrical X-ray diffuse scattering component.

intensity for Specimen 3 is higher than that for Specimen 4 by approx. 25 times and the volume of discrete large particles is hundreds times greater according to TEM data. This can be accounted for by the fact that the quantity of particles decreases significantly with an increase in annealing duration because medium sized particles form by a dissolution and precipitation growth mechanism for which larger particles grow at the expense of the dissolu- tion of smaller ones. One should also bear in mind that an increase in annealing temperature from $650{ }^{\circ} \mathrm{C}$ to $1000^{\circ} \mathrm{C}$ reduces the supersaturation of the solution. This is the primary cause of the dissolution of small particles.

\section{Conclusion}

Combined TEM, metallographic and X-ray diffuse scattering studies of the structures produced by the decomposition of oxygen solid solution in silicon revealed regularities of structural transformations occurring during the decomposition of oxygen solid solution in silicon at different temperatures. These regularities originate from the differences in the energy parameters of different process stages.

For annealing at $450{ }^{\circ} \mathrm{C}$, solid solution decomposition occurs at high supersaturation degrees, and concentration inhomogeneity regions may form at an early decomposition stage over the actual annealing time (up to $40 \mathrm{~h}$ ).

With an increase in the temperature of subsequent annealing to $650{ }^{\circ} \mathrm{C}$, local regions with above-average oxygen supersaturation degrees noticeably increase the efficiency of oxygen solid solution decomposition in comparison with that for annealing with the same duration and at the same temperature but without a preliminary $450{ }^{\circ} \mathrm{C}$ anneal (X-ray diffuse scattering resolved large microdefects). TEM-invisible coherent oxide precipitates form after annealing for $40 \mathrm{~h}$ and their quantity increases with annealing duration.

Probably, in accordance with the phase diagram, at a higher oxygen concentration and a somewhat higher annealing temperature the solid solution supersaturation may remain high and coherent precipitation may intensify due to higher diffusion rates. Further increase in annealing temperature to $T>1000{ }^{\circ} \mathrm{C}$ reduces the supersaturation but increases the diffusion rate. This results in a more intense formation of the largest precipitates at the expense of the smaller ones. Once the precipitate sizes become sufficiently large the elastic stresses start to relax leading to partial incoherence and the generation of dislocations around the particles. It is this type of defect structure that seems to be the most efficient getter.

\section{References}

1. von Ammon W., Sattler A., Kissinger G. Defects in monocrystalline silicon. In: Kasap S., Capper P. (eds) Springer Handbook of Electronic and Photonic Materials. Springer, 2017. https://doi. org/10.1007/978-3-319-48933-9_5

2. Falster R., Voronkov V.V., Resnik V.Y., Milvidskii M.G. Thresholds for effective internal gettering in silicon wafers. In: High Purity Silicon VIII: Proceedings of the International Symposium, 2004; 2004 05: 188-201.

3. Huff H.R. Silicon. In: Encyclopedia of Materials: Science and Technology. Elsevier, 2001: 8486-8497. https://doi.org/10.1016/B0-08043152-6/01517-5
4. Isomae S., Ishida H., Itoga T., Hozawa K. Intrinsic gettering of copper in silicon wafers. J. Electrochem. Soc., 2002; 149(6): G343-G347. https://doi.org/10.1149/1.1475694

5. Bulyarskiı̌ S.V., Svetukhin V.V., Prikhod'ko O.V. Spatially inhomogeneous oxygen precipitation in silicon. Semiconductors, 1999; 33(11): 1157-1162. https://doi.org/10.1134/1.1187839

6. Bulyarskiǐ S.V., Svetukhin V.V., L’vov P.E. Thermodynamics of complex formation and defect clustering in semiconductors. Semiconductors, 2000; 34(4): 371-375. https://doi.org/10.1134/1.1187990

7. Geranzani P., Pagani M., Pello C., Borionetti G. Internal gettering in silicon: Experimental and theoretical studies based on fast and slow 
diffusing metals. Solid State Phenomena, 2002; 82-84: 381-386. https://doi.org/10.4028/www.scientific.net/SSP.82-84.381

8. Sueoka K. Modeling of internal gettering of nickel and copper by oxide precipitates in Czochralski-Si wafers. J. Electrochem. Soc., 2005; 152(10): G731-G735. https://doi.org/10.1149/1.2001208

9. Ital'yantsev A.G. Generation of nonequilibrium point defects and its accompanying effects in the volume of semiconductors under physicochemical effects on the surface of crystals. Diss. Dr. Sci. (Phys.Math.). Chernogolovka, 2009, 280 p. (In Russ.)

10. Milvidsky M.G. Contaminant gettering in dislocation-free silicon wafers. Izvestiya Vysshikh Uchebnykh Zavedenii. Materialy Elektronnoi Tekhniki = Materials of Electronics Engineering, 2009; (1): 6-12. (In Russ.)

11. Voronkov V.V. Formation of voids and oxide particles in silicon crystals. Mater. Sci. and Eng. B, 2000; 73(1-3): 69-76. https://doi. org/10.1016/S0921-5107(99)00436-5

12. Bublik V.T., Matsnev S.Yu., Shcherbachev K.D., Mezhenny̌̌ M.V., Mil'vidskiı̌ M.G., Reznik V.Ya. Diffuse X-ray scattering study of the formation of microdefects in heat-treated dislocation-free large-diameter silicon wafers. Physics of the Solid State, 2003; 45(10): 1918-1925. https://doi.org/10.1134/1.1620095

13. Voronkov V.V., Falster R. Grown-in microdefects, residual vacancies and oxygen precipitation bands in Czochralski silicon. J. Crystal Growth, 1999; 204(4): 462-474. https://doi.org/10.1016/S00220248(99)00202-X

14. Bublik V.T., Shcherbachev K.D., Voronova M.I., Zhevnerov E.V. On the technique of absolutization of diffuse scattering intensity measurements based on thermal diffuse scattering measurements. J. Synch. Investig., 2010; 4: 773-777. https://doi.org/10.1134/ S1027451010050149

15. Pietsch U., Holý V., Baumbach T. High-Resolution X-Ray Scattering From Thin Films to Lateral Nanostructures. New York: Springer-Verlag, 2004, 408 p. https://doi.org/10.1007/978-1-4757-4050-9

16. Krivoglaz M.A. X-Ray and Neutron Diffraction in Nonideal Crystals. Berlin; Heidelberg: Springer-Verlag, 1996, 420 p. https://doi. org/10.1007/978-3-642-74291-0 